\title{
Direitos humanos de crianças e adolescentes no arquipélago do Marajó/PA: desafios e possibilidades do território
}

\section{Human rights of children and adolescents in the archipelago of Marajó/PA: challenges and possibilities of the territory}

\author{
Jacqueline Tatiane da Silva Guimarães*
}

Resumo: Refletimos sobre a situação da infância na Amazônia marajoara e os desafios para a garantia de direitos humanos. Iniciamos, discorrendo sobre a entrada das demandas da infância na agenda das políticas públicas brasileiras, dando especial destaque aos conceitos de "rede" e "sistema". Posteriormente, sobre a amplitude, diversidade e heterogeneidade do Marajó que nos impõem diferentes desafios para a efetivação de políticas públicas na Amazônia. Para a obtenção dos dados aqui apresentados, recorremos à pesquisa-ação, que pautouse em levantamento bibliográfico, documental e de campo. Analisamos notícias expostas em jornais eletrônicos e entrevistas que foram realizadas com os profissionais que atuam na rede sociojurídica dos municípios do Marajó Ocidental/PA. Consideramos que há uma complexa demanda a ser enfrentada pelos municípios marajoaras, sendo resultado da amplitude de seu território que concentra uma população que vive em situação de extrema pobreza, contraditoriamente, num espaço de extensa riqueza natural.

Palavras-Chave: Direitos Humanos. Infância. Amazônia Marajoara.

Abstract: We reflected on the situation of children in the Amazonian Marajoara and the challenges for guaranteeing human rights. We started by discussing the entry of childhood demands on the Brazilian public policy schedule, with special emphasis on the concepts of "network" and "system". posteriorly, about the amplitude, diversity and heterogeneity of Marajó, that imposes on us different

\footnotetext{
${ }^{*}$ Doutora em Educação, Mestre em Serviço Social e Assistente Social pela Universidade Federal do Pará (UFPA). É professora adjunta A da Faculdade de Serviço Social do Campus Universitário do Marajó/Breves da UFPA (FACSS/CUMB/UFPA).
} 
challenges for the implementation of public policies in the Amazon. To obtain the data presented hede, we used action research, which was based on a blibliographic, documentary and Field survey. We analyzed news exposed in electronic newspapers and interviews that were conducted with professionals working in the socio-legal network of the municipalities of Marajó Occidental/PA. We consider that there is a complex demand to be faced by the municipalities of marajoara, resulting from the breadth of their territory that concentrates a population that lives in a situation of extreme poverty, contradictorily, in an area of extensive natural wealth.

Keywords: Human Rights. Childhood. Amazon Marajoara.

\section{Introdução}

As inquietações registradas nestas páginas resultam de trajetória de pesquisa no tema da história da infância paraense vivida pela pesquisadora ao longo do doutorado (2012 a 2016), e que foram amadurecidas e ganharam corpo e espírito nas ações de pesquisa, ensino e extensão materializadas no Programa Direitos Humanos, Infâncias e Diversidade no Arquipélago do Marajó (DIDHAM), iniciados em 2017, a partir das primeiras vivências na região adensada às constatações quanto aos cruéis registros sobre a realidade vivida pela infância neste território.

Ao longo de quatro anos ${ }^{1}$, mesmo com as restrições impostas pela pandemia do novo COVID-19 (SARS-CoV-2 - Severe Acut Respiratory Syndrome Coronavirus 2), tivemos em constante diálogo com profissionais que atuam diretamente em instituições voltadas para a proteção da infância, a fim de compreender como estes se organizam, quais os desafios que enfrentam e as percepções que possuem sobre o que seriam os direitos humanos de crianças e adolescentes no Marajó. Tomando essas considerações iniciais, partimos para o

\footnotetext{
${ }^{1}$ Na presente pesquisa apresentamos os resultados ampliados e atualizados de artigos que tiveram como recorte o município de Breves, durante os anos de 2017 e 2018, tomando para análise as perspectivas dos profissionais que atuam na Rede de Proteção da Infância e Juventude (GUIMARÃES, 2018a; GUIMARÃES, 2018b).
} 
questionamento principal: quais os desafios encontrados pelos profissionais no momento de garantir direitos humanos de crianças e adolescentes no Marajó?

O Arquipélago do Marajó é um território que comumente tem notoriedade nacional em decorrência das problemáticas sociais e econômicas que atingem os seus municípios, que figuram entre os que possuem os mais baixos Índices de Desenvolvimento Humano (IDH), dentre os quais destacam-se os municípios de Melgaço, Chaves e Bagre. Dentro dos parâmetros do IDH, o estado do Pará possui oito municípios com o IDHM muito baixo, sendo seis da região do Marajó ${ }^{2}$.

Fatores como a ausência de saneamento básico e água potável, aliada a uma estrutura de saúde pública ainda incompleta incidem de modo negativo em vários aspectos na vida dos sujeitos marajoaras. Infelizmente, para os que se debruçam sobre a realidade marajoara não seria de surpreender que num momento de expansão do novo coronavírus, que até então, em fins do ano passado e início deste, estava atingindo os países europeus, ao eclodir como uma verdadeira situação de emergência mundial, iria vulnerabilizar ainda mais o Marajó.

Logo, no início deste ano observamos o avanço da pandemia nas principais periferias do mundo, atingindo as comunidades ribeirinhas da Amazônia, em que no mês de maio foram realizadas diferentes matérias sobre o aumento de casos de contaminação em regiões como Breves e municípios vizinhos, gerando um verdadeiro colapso na rede de saúde pública e no sistema funerário3. Então, o país volta as suas atenções para a realidade marajoara conhecendo a sua frágil estrutura para a efetivação de políticas públicas.

Todavia, antes destes acontecimentos, a região também era conhecida pelos casos de trabalho infantil, abuso e exploração sexual de crianças que ocorrem em seus rios, ruas e florestas. Apesar de ser uma realidade que perdura por muito tempo na região, infelizmente, passou a ser conhecida pelo país somente a partir de 2006, com denúncias oficialmente registradas junto à

2 Informações sobre a metodologia, os objetivos e a natureza do IDH estão disponíveis em https://www.br.undp.org/content/brazil/pt/home/idho/conceitos/o-que-e-o-idh.html.

3 Esta situação foi registrada pela mídia local e também exibida em rede nacional em formato de série intitulada "A Covid-19 no Marajó" que podem ser encontrada no Jornal Eletrônico G1 Pará (de 01/07/2020), e enquanto matéria escrita atende pelo título "Breves enfrenta colapso da saúde e caos no sistema funerário durante a pandemia de Covid-19". 
Câmara Federal, gerando pequenos, mas importantes resultados que ainda necessitam de continuidade para a sua efetivação. Após treze anos, em 2019, o território marajoara volta a ter visibilidades enquanto lugar de miséria e de desproteção da infância demarcada por visitas da Ministra da Mulher, da Família e dos Direitos Humanos e do tão famigerado discurso da "fábrica de calcinhas" como estratégia para o combate ao abuso e exploração sexual de crianças e adolescentes ${ }^{4}$.

Contudo, também salientamos as dificuldades em termos acesso a dados sistematizados quanto aos casos de violações de direitos humanos, seja pela não publicização por parte das instituições competentes ou pela inabilidade na produção destes dados que são imprescindíveis para o fortalecimento das políticas públicas. Esta constatação ao longo de nossas atuações no Marajó foram fundamentais para a construção de uma proposta de pesquisa que também se desse num marco interventivo, na medida em que realizarmos momentos de capacitações estávamos pautados numa perspectiva do diálogo que também tinham como objetivo compreender os desafios que os profissionais que atuam na rede de proteção da infância enfrentavam no seu cotidiano.

Este contexto deve ser problematizado, registrado, analisado a fim de construirmos propostas coletivas para o enfrentamento e fortalecimento de sua população. Neste sentido, destacamos que este estudo apresenta parte dos resultados de pesquisa, aliadas às ações extensionistas, que foram iniciados ainda no mês de agosto de 2017, então, o que será apresentado na verdade, são registros de vivências e experiência como docente, pesquisadora e moradora desta região.

No presente artigo temos como recorte de abordagem a situação da infância na Amazônia marajoara, abordando sobre as diferentes formas de violações de direitos humanos, bem como os desafios que devem ser enfrentados e os aspectos que devem ser pensados a fim de se superar as abordagens e estratégias superficiais e pontuais que não conseguem contemplar a complexidade que envolve esta região. Para a obtenção dos dados aqui

\footnotetext{
4 A primeira visita do atual governo ocorreu no dia 12 julho de 2019, para a realização de Audiência Pública para a divulgação e articulação do Programa "Abrace o Marajó" (O Liberal, 10/07/2029) que iremos tratar mais adiante. Mas esta reunião culminou na recente visita do atual Presidente da República ao município de Breves/PA no dia 08/11/2020 (CARNEIRO, 08/10/2020).
} 
apresentados, considerando o recorte da rede sociojurídica, recorremos à pesquisa-ação (SEVERINO, 2007), que pautou-se no levantamento bibliográfico, documental e de campo, em que foram realizadas entrevistas semi-estruturadas com os profissionais que atuam no Sistema de Justiça dos municípios de Breves, Melgaço e Portel (Marajó Ocidental/PA), como a Defensoria Pública, o Ministério Público e o Fórum de Justiça.

Aliados a estes dados também utilizamos como fontes matérias e notícias que se referiam à infância do Marajó a partir de levantamento realizado no sistema de busca e pesquisa Google, utilizando os seguintes termos: "infância", "criança" e "Marajó". A partir destas opções metodológicas pretendemos oferecer bases para reflexões que nos permitam compreender sobre quais (1) propostas de desenvolvimento econômico e social vem sendo pensadas para "um" Marajó? (2) Qual a lógica que vem se perpetuando para a proteção de crianças e adolescentes marajoaras?

Iniciamos as nossas reflexões discorrendo sobre a entrada das demandas da infância na agenda das políticas públicas brasileira, dando especial destaque aos conceitos de "rede" e "sistema" que são fundamentais para a efetivação da proteção integral da criança, no qual tratamos sobre a sua articulação com os conceitos de intersetorialidade. Para as definições quanto às categorias "rede" e "sistemas" recorremos a Johnson (1997) e Giddens e Sutton (2017) e para o conceito de intersetorialidade utilizamos Junqueira (2004), Nascimento (2010) e Junqueira, Inojosa e Komatsu (1997).

Posteriormente, problematizamos a extensão e diversidade do território amazônico, consequentemente o marajoara, apresentando uma caracterização do Arquipélago do Marajó, tratando sobre a sua amplitude, diversidade e heterogeneidade, indicando-o enquanto um território plural, não sendo tão somente Marajó, mas sim Marajós, assim como as representações sociais e discursos hegemônicos que a envolvem e acabam por impedir a efetivação de políticas públicas inclusivas e equitativas na Amazônia. Para traçarmos uma caracterização socioeconômica, política e cultural dos Marajós utilizamos os dados expostos no "Cadernos do Marajó - Edição Especial 40 dias de Marajó com Coronavírus", publicado no mês de maio deste ano. 
Consideramos que há uma complexa demanda a ser enfrentada pelos municípios marajoaras, em decorrência da amplitude de seu território que concentra uma população que vive em situação de extrema pobreza, contraditoriamente, num espaço de extensa riqueza natural. Não temos a pretensão de oferecer respostas fechadas e definitivas para um quadro tão complexo, mas sim construir caminhos coletivos que pensem intervenções que se dêem em rede e que sejam interdisciplinares, interprofissionais, interinstitucionais, interpolíticas e fundamentalmente intersetorial.

\section{A efetivação dos direitos de crianças e adolescentes no brasil e os conceitos de rede e sistema}

A trajetória para a compreensão da criança enquanto sujeito de direito foi longa, significando a saída de um entendimento de controle e coerção da infância pobre para a construção de dispositivos que não buscassem puni-las e sim protegê-las integralmente, independente de fatores como classe, raça, etnia, religião e gênero.

Em 13 de julho de 1990 é promulgada a Lei 8.069/1990, que se trata do Estatuto da Criança e do Adolescente (ECA), surgindo como um dispositivo que objetiva regulamentar os direitos de crianças e adolescentes previstos e assegurados na Constituição Federal de 1988, especificamente nos artigos $227 \mathrm{e}$ 228, e acordado na Convenção Internacional dos Direitos da Criança, aprovada pela Assembleia Geral das Nações Unidas, ambas realizadas em 1989.

No ECA e na $\mathrm{CF} / 88$ revelam-se o entendimento e princípios de integralidade e totalidade que tomam a criança como sujeito de direito e em condições particulares de desenvolvimento físico, mental, intelectual, psicológico, sexual e afetivo. Há a retirada do modelo de institucionalização, pautado no caráter punitivo, controlador que pretendia proteger o Estado e uma sociedade elitista de crianças e jovens que por esta ótica seriam potenciais infratores, então menores em situação irregular, definição presente no Código de Menores de 1979 (SIMÕES, 2014). Além disso, também se perde de mira, ao menos no plano formal jurídico, a perspectiva de culpabilização da família, . 
Amplia-se a noção de proteção, acolhimento e cuidado não focando as responsabilidades somente a um grupo social ou instituição. Substituiu-se o modelo fragmentado, vertical, autoritário e punitivo. Deste modo, destacam-se os seguintes aspectos e termos: integral, sistema, rede e intersetorial.

O Estatuto da Criança e do Adolescente específica os direitos gerais da infância e da adolescência, propondo formas de gerir a garantia destes direitos a partir de um Sistema, no qual todos possam ser responsáveis pela criação do Sistema de Garantia de Direitos da Criança e do Adolescente (SGDCA). O SGDCA começa de fato em 1988 com a Constituição Federal e ganha impulso com o referido estatuto.

Os sistemas correspondem às ações integradas das atuações governamentais e não governamentais. Nesta nova proposta não há mais somente um responsável soberano pela concretização da proteção da infância, que até então estava focada na figura do Estado. Atendendo a uma perspectiva que visa articular e integrar, constrói-se um modelo de co-responsabilidade, pautando-se nas seguintes frentes: família, Estado, comunidade e sociedade, justamente a fim de empreender uma concepção de rede em favor da proteção dos direitos da criança e do adolescente.

A construção de um sistema pressupõe que este deve se efetivar a partir de uma perspectiva de trabalho e gestão que seja integrada e interligada em redes, com agendas compartilhadas e coletivizadas, ou melhor, dialogadas. Ao nos reportamos à compreensão de rede, cabe destacar a definição de Johnson (1997, p. 190) ao tratar desta como um método utilizado por sociólogos:

\begin{abstract}
o método de rede supõe que experiência, comportamento e resultados individuais dependem mais do ponto em que pessoas estão localizadas nas várias redes do que de quem eles são como indivíduos. Esse fato tem origem na idéia de que as redes tanto impõem restrições que limitam as opções, como proporcionam recursos que permitem que indivíduos atuem de várias maneiras. Assim, diferenças entre pessoas podem ser compreendidas por elas pertencerem a redes diferentes ou por estarem localizadas de modo diferente na mesma rede.
\end{abstract}

A utilização de métodos/trabalhos que visam se organizar em rede relaciona-se com a intenção de possibilitar estratégias que compreendam ações de indivíduos que estão localizados em diferentes pontos, ou seja, pressupõe "um 
conjunto de relações que ligam pessoas, posições sociais ou outras unidades de análise, como grupos e organizações" (JOHNSON, 1997, p. 190).

Giddens e Sutton (2017), ao oferecerem uma definição prática ao termo, indicam que a rede se refere a um conjunto de vínculos informais e/ou formais que acabam por conectar as pessoas entre si, tanto em formas de organização mais livres quanto na vida social. Mas como se daria tal processo quando aplicado às políticas de proteção da infância e da adolescência? Esta não seria a mera disposição de instituições e equipamentos existentes nos municípios. O projeto Tecendo Redes do grupo Marista em parceria com o Ministério Público do Paraná, destaca que:

\begin{abstract}
A rede é uma forma de organização capaz de responder ao desafio da proteção integral. Não é uma entidade, não é um “objeto", não é uma "rede de computadores" - que segue uma lógica "matemática" - desprovida de emoções. O trabalho em rede é uma forma coletiva de planejar e organizar entidades (governamentais e não governamentais), comunidades, fluxos e protocolos de atendimento, recursos e ações a fim de efetivar a "proteção integral" que o ECA há tanto apregoa (PARANÁ, 2014; p. 12).
\end{abstract}

Ao ter-se como especial fundamento para a garantia de direitos da infância a proteção integral, não há como desconsiderar que as ações dos diferentes sujeitos e instituições devem ocorrer de modo coletivo e integrado. Salientando, que as instituições, órgãos e organizações independentemente de atenderem diretamente a infância, devem realizar esforços em ações que visem contemplar crianças que estejam em situação de vulnerabilidade e risco social.

Mas como efetivar uma ação que seja integrada? Para tal questionamento recorremos também ao importante conceito da intersetorialidade. Sueli Nascimento (2010) ao tratar sobre a importância da intersetorialidade entre as políticas públicas nos indica as suas contribuições para a execução das políticas setoriais no atendimento de determinadas demandas, possibilitando a articulação entre diferentes instituições governamentais e a sociedade civil, reunindo diferentes saberes técnicos $\mathrm{e}$ agendas coletivas para o compartilhamento de objetivo comuns de especialistas de diferentes áreas.

O trabalho intersetorial não substituiria o setorial, quando na verdade estes são convergentes, significando o reconhecimento dos saberes que foram resultado da integração entre as diferentes áreas setorializadas. Contudo, é 
importante ratificar que não seria um processo simples sendo uma mera justaposição de projetos setorializados (NASCIMENTO, 2010), quando na verdade envolve o fortalecimento de canais de comunicação e diálogo entre as diferentes políticas públicas, por meio de profissionais que munidos de conhecimentos e saberes de diferentes e diversas áreas passam a mobilizar estratégias de caráter interdisciplinar e interprofissional para atender determinadas demandas.

Neste sentido, do mesmo modo que Junqueira, Inojosa e Komatsu (1997, p. 24) compreendemos que a intersetorialidade significa a "articulação de saberes e experiências no planejamento, realização e avaliação de ações, com o objetivo de alcançar resultados integrados em situações complexas". Representando uma nova possibilidade para a resolução de demandas que atingem a população de determinados territórios, haja vista que permite a visualização integrada de problemáticas sociais, assim como de suas soluções (JUNQUEIRA, 2004).

$\mathrm{Na}$ intenção de realizar ações que se concretizem em rede para a garantia de direitos humanos de grupos vulneráveis temos equipamentos como Conselho Tutelar, Centros de Referência em Assistência Social, Centros Especializados de Referência em Assistência Social, Delegacia da Mulher, Abrigos, Defensorias Públicas, Conselhos Municipais de Direitos da Criança e do Adolescente e Ministério Público. Entretanto, precisamos questionar quais estratégias são tomadas, bem como metodologias e princípios para que esta rede realmente funcione para que sejam executadas ações integradas para a proteção da infância em territórios amplos e repletos de desafios para a criação de canais de comunicação e diálogo.

Diante do exposto, frisamos a importância de avaliações e pesquisas que devem ser realizadas seja pelos órgãos oficialmente competentes ou pela sociedade civil e movimentos sociais a fim de verificar e analisar constantemente o modo como são planejadas e executadas as ações realizadas pelos mencionados equipamentos, observando como elaboram suas agendas no sentido de um trabalho integrado. Não no sentido de uma fiscalização que interroga e condena, mas que construa junto com os profissionais e gestores projetos e planos que 
contemplem as particularidades de seus territórios, considerando limites e possibilidades para a sua organização.

\section{Os direitos humanos de crianças e adolescentes na Amazônia brasileira}

Antes de adentrar nas particularidades do território marajoara, é importante traçar linhas de reflexões que permitam o entendimento de que esta região é atingida pela mesma lógica e processo de ocupação que se deu na Amazônia, gerando modos específicos de posição da região amazônica na expansão do capital. Todavia, resguardando particularidades ao território marajoara.

Conforme Teixeira (2008) a Amazônia é a última fronteira de biodiversidade natural e cultural ocupada pelo processo de expansão e mundialização do capital, tornando-se espaço de polarização do capital e trabalho e palco de uma modernização conservadora que explora não somente o meio ambiente, mas pessoas, vidas. Na atual conjuntura este processo de expansão vem se dando de forma mais acirrada em tempos de incertezas políticas, mas não de dúvidas quanto à exploração de recursos naturais e de força de trabalho de uma maioria que não possui corpos brancos5.

Dentro da totalidade do desenvolvimento capitalista é dado um papel específico para a Amazônia, tendo sido iniciado ainda com a Acumulação Primitiva e o Sistema Colonial, mas que se aprofundou e se intensificou no período da expansão imperialista com a retirada de recursos naturais de áreas periféricas. Decorrendo de uma "sina colonial" de exploração de recursos naturais e da força de trabalho (FIALHO NASCIMENTO, 2010).

A Amazônia é um extenso território latino-americano, que abrange o9 países (Brasil, Bolívia, Peru, Equador, Colômbia, Venezuela, República da

\footnotetext{
$5 \mathrm{Na}$ Amazônia possuímos uma população que em sua maioria se autodeclara como parda. Nos estados da região norte $19,30 \%$ se declaram brancos, $7,1 \%$ como pretos e $71,80 \%$ como pardos. Conforme os parâmetros do IBGE, pessoas pretas e pardas são consideradas negras, contudo, também compreendemos a complexidade do debate etnico-racial numa região em que a população ainda tem muito a aprender e conhecer quanto a sua história e cultura indigena e africana.
} 
Guiana, Suriname e Guiana Francesa), sendo que o Brasil possui $45 \%$ dessa extensão geográfica, enquanto que a Amazônia brasileira é 60\% do território nacional (FIALHO NASCIMENTO, 2010). A Amazônia Legal abarca toda a Região Norte (Acre, Amapá, Amazonas, Pará, Tocantins, Rondônia e Roraima) e parte das regiões do Nordeste (Maranhão) e do Centro-Oeste (Mato Grosso).

Ao problematizar os desafios impostos pela Amazônia ao Serviço Social, Teixeira (2008) destaca o quão extenso e complexo lidar com as problemáticas advindas de um modo de produção que impõe um modelo de desenvolvimento, e acrescentamos, de modernidade, que se faz violento e genocida. E este desafio não será sentido somente pelo Serviço Social, seja enquanto campo de atuação profissional ou área de produção do conhecimento, mas por todos que pretendem concretizar ações que visem garantir direitos humanos para a população amazônida.

E este panorama se mostra mais do que atualizado na atual conjuntura política atingida por uma agenda extremamente regressiva e neoliberal. Fearnside (2019) destaca que com as eleições de 2018 se formou um quadro de ameaças diretas ao meio ambiente e aos direitos humanos para o Brasil e a Amazônia brasileira, em que o que inicialmente seria a possibilidade de extinção do Ministério do Meio Ambiente passou a ser a redução das suas atribuições quanto às questões importantes como fiscalização e controle do desmatamento.

Cunha (2019) ao fazer uma projeção, destaca que estas medidas foram iniciadas com as modificações ocorridas na Política de Regularização Fundiária na Amazônia (PRFA), conhecido com Programa Terra Legalb, mas que esta mesma estratégia já havia aprofundado as fragilidades existentes no texto de 2009.

Temos uma região, que nos discursos externos, é tomada por uma concepção restrita de meio ambiente e de biodiversidade centrada na noção de espaço das águas, dos minérios, das florestas, ou seja, as tão propaladas "riquezas

\footnotetext{
${ }^{6}$ Lançado em 2009 pelo Governo Federal e implementado pelo Ministério do Desenvolvimento Agrário (MDA), o Programa Terra Legal, ao estar baseado na lei 11.952/2009, tinha por objetivo acelerar o processo de regularização de pelo menos 300 mil ocupações informais, tornando-as em terras públicas na Amazônia Legal (imazon.org.br).
} 
naturais". Perspectiva que exclui e aniquila sujeitos sociais diversos. Cabe reiterar que este lugar, este território, é espaço de pessoas/sujeitos que possuem uma diversidade de vivências. De acordo com dados do Instituto Brasileiro de Geografia e Estatística (IBGE), de 2019, a Amazônia Legal possui 28.990.627 habitantes. É lugar de riquezas naturais, mas possui uma significativa parcela populacional que está entre os altos índices de vulnerabilidade social.

Não há como não destacar que os municípios da região amazônica estão entre os que possuem os mais baixos IDH, revelando os desafios desta região, de dimensões continentais, para a garantia de direitos humanos de todas as ordens, atingindo famílias e crianças que estão em situação de pobreza. Conforme a "Agenda pela Infância e Adolescência na Amazônia" elaborada pelo Fundo das Nações Unidas para a Infância (UNICEF),

\begin{abstract}
Os indicadores sociais mostram que as crianças na Amazônia têm maior risco de morrer antes de 1 ano de idade e de não completar o ensino fundamental. Além disso, a taxa de gravidez na adolescência é alta, e as meninas e os meninos na região estão vulneráveis às mais variadas formas de violência, incluindo o abuso, a exploração sexual, o trabalho infantil e o homicídio. Quando todas essas variáveis são avaliadas a partir de um recorte de raça e etnia, percebe-se que entre os grupos minoritários, como indígenas e quilombolas, o quadro é ainda mais grave (UNICEF, 2018, p. 6)
\end{abstract}

Salientamos que os processos que envolvem a Amazônia para lidar com problemáticas como estas estão constantemente relacionadas às falhas de fiscalização, monitoramento e comunicação para que, então, sejam realizadas notificações e a visualização de situações de violações de direitos que em sua maioria se manifestam como negligência, violência sexual, violência psicológica, trabalho infantil, tráfico humano e outras formas de discriminação como o racismo e a homofobia. Os estados que compõem a Amazônia Legal (que correspondem a nove dos 26 estados brasileiros), em 2018, correspondiam a 10.4\% dos casos registrados no Disque 100 de um total de 152.178 registros (BRASIL, 2019).

Contudo, não podemos homogeneizar tais desafios nem mesmo quando se trata de um mesmo território, haja vista que a Amazônia se constitui em um espaço extremamente heterogêneo e amplo, no qual iremos observar que alguns municípios e estados serão mais atingidos que outros seja pela desigualdade 
social quanto pelas diferentes formas de manifestação da violência. A exemplo disso, o Pará que é o segundo maior estado do Brasil, tendo as suas dinâmicas influenciadas pelos rios e estradas, em 2018, em estudo realizado pela Polícia Rodoviária Federal (PRF), foi constatado que é o segundo com mais pontos de exploração sexual infantil nas rodovias, computando 232 pontos, num total de 2.487 pontos vulneráveis (G1 Pará, 15/05/2018).

São milhares de crianças ribeirinhas, quilombolas e indígenas que distantes dos centros urbanos paraenses estão tendo os seus direitos violados em navios, lanchas e rabetas, assim como crianças pretas e pardas que vivem nas periferias paraenses tão próximas, mas tão longe da rede de proteção de direitos humanos. Cotidianamente faz-se necessário reforçarmos ações interventivas e investigativas que visem fortalecer o sistema de garantia de direitos da infância na Amazônia.

Vivemos em uma sociedade que estabelece marcadores sociais que irão estabelecer hierarquias que darão bases às históricas desigualdades sociais e econômicas, que seriam de classe, geração, gênero, raça e etnia, porém devemos estar fortemente atentos aos marcadores que se referem ao território, haja vista que este impõe diferentes demandas e dinâmicas não somente aos sujeitos, mas também às instituições.

\section{A pluralidade do território marajoara: características e aspectos socioeconômicos}

Esta região compreende um território de $49.606 \mathrm{~km}^{2}$, formado por um conjunto de ilhas ricas em recursos hídricos e biológicos, estando totalmente situado no estado do Pará (BRASIL, 2006). Possui uma população estimada em 564.199 habitantes, estando 43\% na área urbana e 57\% na rural. Deste total de habitantes, $48 \%$ são mulheres e $52 \%$ são homens. Quanto à identidade étnicoracial, o,81\% corresponde a população amarela, o,03\% indígena, 16,28\% branca e 82, 89\% negra (OBSERVATÓRIO DO MARAJÓ, 2020).

Este extenso território, repleto de diversidade, forma o Arquipélago do Marajó que abarca 16 municípios que estão divididos em 3 microrregiões: Arari, Furos de Breves e Microrregião de Portel. A primeira microrregião localiza-se na 
área de integração do Marajó Oriental, compreendendo os seguintes municípios: Cachoeira do Arari, Chaves, Muaná, Ponta de Pedras, Salvaterra, Santa Cruz do Arari e Soure. No Marajó Oriental há 181.092 habitantes, em que 55\% estão na área urbana e $45 \%$ na rural, estando composto étnico e racialmente por o,86\% amarelos, o,03\% indígenas, $15 \%$ brancos e $84 \%$ negros. Em questão de gênero, 48\% mulheres e 52\% homens. (OBSERVATÓRIO DO MARAJÓ, 2020).

Os municípios de Afuá, Anajás, Breves, Curralinho e São Sebastião da Boa Vista estão na Microrregião dos Furos de Breves, enquanto que os municípios de Bagre, Gurupá, Melgaço e Portel estão na Microrregião de Portel. Estas duas microrregiões estão no Marajó Ocidental, que totaliza 409.747 habitantes, distribuídos $36 \%$ na área urbana e $64 \%$ na área rural. Quanto às questões de gênero e étnico-racial, temos os seguintes dados: $48 \%$ são mulheres e $52 \%$ são homens, enquanto $0,68 \%$ se autodeclaram amarelos, $0,01 \%$ como indígenas, $17 \%$ seriam brancos e $82 \%$ correspondem a indivíduos negros.

Dos 16 municípios marajoaras, 14 estão nas piores colocações do ranking do IDH municípios, excetuando-se somente Salvaterra e Soure que estão em uma posição mediana7. Pontuamos que esses municípios ficam a três horas (de lancha rápida) de distância da capital paraense, Belém, o que nos faz deduzir ser um fator que contribui de modo positivo para que Soure e Salvaterra tenham melhores ofertas de serviços, em decorrência de estarem ao alcance do governo estadual, possibilitando uma melhor visibilidade, inclusive para o turismo.

Compreendemos que a situação do Marajó Oriental não seria tão positiva, haja vista que $39,60 \%$ de sua população não possui serviço de abastecimento de água por rede geral de distribuição e 54,24\% não possui banheiro e água encanada. A situação se torna mais grave quando observamos também que 75,50\% de seus moradores não têm esgotamento sanitário, aliado a isto $83 \%$ possuem casas com paredes inadequadas, ou seja, não possuem revestimento externo de alvenaria, que seriam materiais indicados para a prevenção da doença de Chagas.

7 Na listagem do Ranking IDHM Municípios 2010, os municípios de Soure e Salvaterra surgem com o IDHM de o, 615 e o,608, respectivamente, que são valores considerados de médio desenvolvimento humano. 
Todavia, no Marajó Ocidental esta situação se intensifica ainda mais, diante do fato de que 77, $58 \%$ não possui serviço de abastecimento de água por rede geral de distribuição e 81,56\% não possuem banheiro e nem água encanada. Destes domicílios 89,60\% possuem paredes inadequadas e 94,87\% não possuem esgotamento sanitário. Nesta região somente Curralinho e Sebastião da Boa Vista possuem plano municipal de saneamento, enquanto na parte Oriental nenhum possui tal plano.

Salientamos que estes dados foram reunidos pelo coletivo Lute sem Fronteira/Observatório do Marajó, que com anos de atuação no arquipélago marajoara, no mês de maio deste ano lançou o documento "Cadernos do Marajó - Edição Especial 40 dias de Marajó com Coronavírus”, após os altos índices alcançados pela região no avanço do SARS-CoV-2 (Severe Acut Respiratory Syndrome Coronavirus 2), ou melhor, o novo Coronavírus (novo Covid-19) (BRASIL, 2020).

Ainda no mês de maio o município de Breves ganhou destaque nacional após a divulgação da pesquisa realizada pela Universidade de Pelotas (RS) que constatou que $25 \%$ da população brevense já teria tido contato com o novo COVID-19 (G1 Pará, 25/05/2020). Ressaltamos que o mencionado município é o polo do Marajó Ocidental, sendo lugar de constante circulação, incluindo os ribeirinhos que precisam ir até a cidade para terem acesso a serviços como caixas eletrônicos, correios e hospitais. Sendo também caminho para Macapá, estado que se destacou pelo avanço da pandemia ${ }^{8}$.

Infelizmente, não seria de surpreender este panorama, considerando as condições que são dadas aos seus moradores. Quanto a este quadro e os dados indicados, verificamos os seguintes aspectos: 1) a população em sua maioria não possui casas adequadas para moradia, sendo em sua maioria casas de madeira e outras em palafitas; 2) ausência de água encanada e potável; 3) ruas sem saneamento básico9; e 4) os municípios, em sua maioria, não possuem uma

\footnotetext{
${ }^{8}$ No período de 21 de maio o estado do Amapá estava com uma taxa de 17,9 mortes para cada 100 mil habitantes, estando entre o estado em situação crítica quanto a expansão do novo coronavírus, juntamente com Amazonas (39,1), Ceará (23.7), Pará (21,5), Pernambuco $(20,1)$ e Rio de Janeiro $(19,8)$ (GARRETT Jr./Revista Exame/23/05/2020).

9 No Marajó como um todo, cerca de $71,4 \%$ dos moradores vivem sem esgotamento sanitário (OBSERVATÓRIO DO MARAJÓ, 2020).
} 
política de planejamento urbano. E o mais grave: as famílias ribeirinhas ficam distantes das unidades básicas de saúde e dos Centros de Referência de Assistência Social, contando com visitas rápidas de profissionais que precisam enfrentar viagens de doze horas dos centros das cidades até as ilhas.

Os municípios que fazem parte do Marajó Ocidental são os que ficam mais distantes da capital paraense, em sua maioria resultando em viagens de mais de dez horas feitas em navios ou seis horas em lanchas rápidas, que não são acessíveis a todos os moradores. Contexto que afeta profundamente a logística e planejamento das instituições que pretendem garantir direitos, gerando problemáticas ligadas a custos.

\title{
Situação da infância marajoara: registrar para dar visibilidade e fortalecer intervenções.
}

\begin{abstract}
No dia 10 de abril de 2006, o Monsenhor Dom José Luiz Azcona, Bispo da Ilha do Marajó, denunciou ao Chefe de Gabinete do Presidente Luiz Ignácio Lula da Silva, Dr. Gilberto Carvalho e ao Presidente da Comissão de Direitos Humanos da Câmara Federal, deputado Luiz Eduardo Greenhalgh (PT-SP), que, dentre outros problemas sociais preocupantes, adolescentes estariam sendo vítimas de exploração sexual no Município de Portel, Estado do Pará, na região do Arquipélago de Marajó (FORMENTINI, 2006) ${ }^{10}$.
\end{abstract}

Acima está exposto um dos trechos do relatório sobre os casos de exploração sexual no município de Portel, vizinho de Breves e Melgaço, tendo sido um marco diante da impunidade perante as violências praticadas contra crianças e mulheres. Sendo fundamental dar visibilidade as ações de denúncias e vigilância realizada por grupos religiosos como a Prelazia do Marajó e a Comissão de Justiça e Paz/Marajó da Conferência Nacional dos Bispos do Brasil

\footnotetext{
${ }^{10}$ Trecho do Relatório sobre Exploração Sexual em Portel, elaborado pelo representante e assessor da Comissão de Direitos Humano e Minorias da Câmara Federal, Amarildo Geraldo Formentini, que acompanhou e registrou os depoimentos das vítimas em 2006. O referido documento, acessado em 14/03/2017 estava disponível na página da Câmara dos Deputados, contudo não se encontra mais publicizado. Outros registros podem ser encontrados no blog do jornalista paraense Hiroshi Bogéa em publicação intitulada "Sefer em dois tempos" e no relatorio, de fevereiro de 2010, produzido pela Comissão Parlamentar de Inquerito da Assembleia Legislativa do Estado do Pará/ALEPA, instituida para apurar a prática de violência e abuso sexual contra criancas e adolescentes no estado Pará, sobretudo os casos da região do Marajó, considerando o periodo de cinco anos (PARÁ, 2010).
} 
(CPJ/CNBB), destacando-se nomes como Dom José Luiz Azcona e Irmã Henriqueta Cavalcante, que passaram junto à população denunciar vereadores, prefeitos, professores e outras autoridades da região que estavam envolvidos em casos de pedofilia, aliciamento de menores e exploração sexual comercial de crianças e adolescentes.

A Comissão Parlamentar de inquérito concluiu os seus trabalhos em 2009, tendo sido também resultado das pressões e visibilidades dadas pela imprensa nacional, como nos jornais Correio Braziliense, Folha de São Paulo e nas redes de televisão Sistema Brasileiro de Televisão (SBT) e a Globo Comunicações (GUEDES, 2012). Desta ação resultou a descoberta de uma rede de exploração sexual e de tráfico de drogas composta por vereadores, empresários, autoridades policiais, servidores públicos e outros representantes políticos do município de Portel.

Contudo, infelizmente, a infância marajoara ainda tem muito a superar, assim como os que se mobilizam em torno dos seus direitos a uma vida digna. Desde então, os casos de violações aumentam demasiadamente, porém, apesar das campanhas de incentivo às denúncias de violações, os números ainda são insignificantes diante de tantos relatos que não entram nas estatísticas oficiais.

Em 31 matérias e notícias que se referiam à infância do Marajó, encontradas em levantamento no sistema de busca Google, entre os anos de 2017 a 2018, identificamos as ênfases nos casos de abusos e exploração sexual, bem como do trabalho infantil, especialmente matérias de denúncia ou de campanhas contra as violações dos direitos humanos da infância e da juventude. Observamos que estas matérias surgiram a partir de abril de 2006, que consideramos ter sido resultado das denúncias empreendidas pelas mencionadas entidades.

Os discursos sobre a região do Arquipélago do Marajó (e não ilha como é referido pela mídia) surgem comumente a partir da dubiedade, sendo em alguns momentos como lugar paradisíaco, repleto de águas, praias e sol, mas também como lugar de exploração sexual infanto-juvenil e do trabalho infantil, no qual nos parece a existência de dois tipos de Marajós: o da infância romântica e o da infância cruel. Enquanto na primeira se reportava a uma infância do passado que rememora os elementos ribeirinhos como brincar nos rios e subir em árvores 
(vividas na parte Oriental), contudo, predominam as de caráter de denúncia quanto às situações de exploração vivida por crianças e adolescentes (experienciadas no Ocidental).

Havendo a recorrência nas matérias de termos como "infância roubada" ou "rouba a infância" ao se tratarem sobre o trabalho infantil e a exploração sexual, se referindo em sua maioria às meninas. No entanto, fica em suspenso em tais textos a seguinte pergunta: quem realmente rouba a infância de crianças do Marajó? As argumentações presentes em blogs e artigos de jornais eletrônicos comumente se referem a uma responsabilização individual de uma problemática que é de caráter social e coletivo, que representam a ausência de poder público e fragilidade de políticas públicas existentes na região. Observe a seguir:

\begin{abstract}
É impressionante o número de pessoas que ainda acham que estão ajudando, fazendo caridade, quando pegam uma menina no interior e trazem para trabalhar em suas casas, disse a advogada Celina Bentes Hamoy, coordenadora do Programa de Enfrentamento ao Trabalho Infantil Doméstico (Petid), coordenado pelo Centro de Defesa da Criança e do Adolescente (Cedeca Emaús),em parceria com 11 entidades dos governos estadual, municipal e federal, Ministério Público, Judiciário e organizações da Sociedade Civil (O Liberal, 10/05/2007).
\end{abstract}

Esta fala é sintomática da situação de que meninas dos interiores do Pará e da Amazônia, de forma prematura são retiradas do convívio familiar e afastadas de suas regiões de origem para terem novas oportunidades nas capitais amazônicas, acreditando que nestes locais irão encontrar a estrutura necessária para o seu desenvolvimento, contudo, ao invés de serem espaços de oportunidades, tornam-se oportunidades para que sejam vítimas do tráfico humano e da exploração sexual.

Na maioria dos municípios marajoaras há poucas oportunidades para que estas crianças e adolescentes possam acessar o nível médio e superior, em que da mesma forma que não existem planos municipais de saneamento básico, a maioria também não possui políticas de cultura e lazer consolidadas. Comumente, são crianças e jovens sem qualquer perspectiva de futuro ${ }^{11}$ que

\footnotetext{
${ }^{11}$ Ao indicarmos a falta de perspectiva de futuro, estamos nos referindo às opções de vida que são oferecidas nos municípios para que estes jovens possam concluir os seus estudos na propria regiao e quem sabe no futuro comporem o grupo de profissionais qualificados para atuarem em seus próprios municípios e assim ascenderem socialmente. Considerando que significativa parcela da
} 
acabam por agregarem valores e comportamentos que acabam por afastá-los do modo de viver ribeirinhos tal qual os vivido por seus pais e avós. É fundamental compreendermos o contexto em que estes sujeitos estão imersos justamente para que não sejam construídos discursos que os responsabilizam individualmente.

Abaixo segue um trecho do texto que trata sobre "Crianças de Marajó se prostituem por hot dog (são exploradas sexualmente)" que nos diz:

No grupo há mais de dez meninas. Elas andam sozinhas, depois da meia noite, pelas ruas vazias de Breves, a maior cidade da ilha de Marajó, um arquipélago de 104 mil km2 no norte do Pará. Elas gritam e dão pulinhos, animadas pela festa logo ao lado, próxima à zona portuária, num galpão com mais de sete metros de pé direito, todo feito de madeira como boa parte das construções na cidade. Não parecem ter mais do que 15 anos. Mas, como é comum em Breves, vestem roupas de adultas: shorts que não chegam à metade das coxas, blusas minúsculas. Na festa, diz uma placa, menores não entram, mas ninguém pede seus RGs. Dentro, na semi escuridão, elas se mesclam às centenas de pessoas, a maioria delas mais velhas, atingidas pela potência de uma caixa de som do tamanho de uma parede, que toca os hits recentes do "melody", uma variação do tecnobrega, música que mistura batidas eletrônicas com ritmos caribenhos.

O repórter está próximo de duas meninas do grupo. Afirmam ter 17 anos e pedem uma cerveja. Pouco depois, sem constrangimento aparente, dizem de maneira seca que, se ele pagar a bebida, poderá escolher uma para sair dali. A prostituição de adolescentes e crianças na Ilha de Marajó foi formalmente denunciada ao governo federal em abril de 2006 pelo bispo local [...], mas a fiscalização, que aumentou, não brecou uma situação já enraizada. A reportagem passou cinco dias na região e viu que crianças e adolescentes se prostituem por dinheiro suficiente para se divertir à noite ou consumir artigos como roupas, celulares ou um simples hot dog (MAGALHÃES, 2009; grifo nosso).

É possível observar uma tentativa em apresentar aos leitores uma argumentação que visa retratar o contexto socioeconômico da região, porém remetendo aos sujeitos envolvidos determinada autonomia quanto a suas vestimentas e estratégias de sobrevivência, não questionando as opções que são oferecidas e a responsabilidade do Estado quanto a esta realidade.

Em cidades com alguns dos piores IDHs (Índices de Desenvolvimento Humano) do país, o dinheiro parece corromper mesmo quem, à primeira vista, não tem nada a ver com o negócio do sexo (MAGALHÂES, 2009; grifo nosso).

população marajoara sobrevive de benefícios sociais como Bolsa Família e o BPC (Benefício de Prestação Continuada). 
É notória a responsabilização da figura feminina, não havendo distinções de crianças e mulheres adultas, recorrendo ao termo "prostituição" ao invés de "exploração sexual infantil", além de remeter aos aspectos culturais da região, levando ao entendimento de uma sexualidade aflorada que seria inata. E continua: "O que conselhos tutelares, policiais e prefeituras tentam entender é como minorar um problema que, segundo eles próprios, têm raízes culturais” e prosseguindo da seguinte forma.

'A avó fez isso, a mãe fez isso', disse o delegado Adalberto Cardoso, de Portel. Para a conselheira tutelar da cidade, Catherine Sousa, esse elemento se manifesta na banalidade com que as pessoas tratam o problema. 'É um tabu, todo mundo sabe, mas ninguém age'. (MAGALHÃES, 2009; grifo nosso)

Há um processo de estigmatização e responsabilização das famílias por situações como a fome, evasão escolar, trabalho infantil e outras formas de violência. Mas poucos se colocam em uma postura de reflexão quanto às reais condições de vivência e sobrevivência destas famílias, pensando sobre as possibilidades e oportunidades que são historicamente negadas a elas. É sempre importante reiterar que crianças e adolescentes que possuem os seus direitos violados são frutos de lares, pais e mães que também são violentados cotidianamente por um Estado ausente e por políticas públicas frágeis que não conseguem alcançá-los.

É necessário quebrarmos este ciclo com proposições mais efetivas que possam confrontar as perspectivas pontuais e conservadoras, tomando os espaços como as escolas e as comunidades como importantes estratégias para a realização de ações educativas não somente com a comunidade local, tida como usuária das políticas públicas, mas também com os profissionais e gestores no sentido de um trabalho preventivo. E, evidentemente, fortalecer e incentivar as políticas sociais a partir de um modelo de gestão que não as coloque como ações de quarta categoria e importância na definição e destinação de recursos públicos.

Em outra matéria de 2017, "A venda de crianças para sexo no Marajó", inicia as suas considerações relatando que repórter da TV Rede Globo ao ter ido a Portel para investigar sobre a exploração sexual de crianças e ao questionar uma senhora sobre por quanto venderia a sua filha de 17 anos, recebeu como resposta 
que seria o valor de 700 reais e ao olhar ao seu redor o mesmo repórter perguntou por quanto esta senhora também cobraria para que o seu amigo passasse uma noite com a outra criança de aparentava ter dez anos idade recebendo a seguinte resposta "por R\$ 10 ou duas cervejas" (MENDES, 2017).

Comumente, destacam os casos que ocorrem nos furos, igarapés e rios, sobretudo os casos que ocorrem no rio Tajapuru, localizado ao norte do município de Melgaço e à direita dos territórios de Breves, dando acesso ao vale Amazônico, Manaus, Macapá, Guiana Francesa, Suriname, Óbidos e Acre (SILVA, 2013), além dos países vizinhos como Suriname e Guiana. Este rio que banha os municípios de Breves e Melgaço se constitui em trajeto para a Zona Franca de Manaus, de constante circulação de navegações, produtos e pessoas, representando também meio de sobrevivência para muitas famílias que passam a ser desconhecidas pelo Estado.

Nesta grande fronteira, chamada de Rio Tajapuru, surgiram "personagens" que passaram a ser chamadas pela mídia e pela população local como "meninas balseiras", termo que estigmatiza meninas que sobem em embarcações para vender camarão, peixe, pupunha, ingá e outros frutos a fim de sustentarem suas famílias, mas que acabam sendo aliciadas e violentadas por homens mais velhos e maiores que elas, que podem estar armados. Abaixo, apresentamos o trecho de um texto que aborda sobre "O drama das meninas balseiras do Marajó":

O delegado de polícia Rodrigo Amorim, de Melgaço, deslanchou a “Operação Meninas do Rio" ao longo do rio Tajapuru, que banha os municípios de Melgaço e de Breves, no arquipélago do Marajó, por onde passa toda a riqueza da Zona Franca de Manaus e cenário de crimes hediondos, como exploração sexual de crianças e adolescentes ribeirinhas e pirataria. $\mathrm{Na}$ abordagem à balsa "Josima", da empresa Tropical Navegação e Transporte Ltda., razão social J. Sabino Transportes, a equipe da polícia civil liderada pelo delegado Rodrigo encontrou uma criança de 11 anos e uma mocinha de 18 anos em condições de prostituição na embarcação, além de diversas outras meninas que não puderam identificar, porque pularam no rio ao avistar a lancha onde estavam os policiais, mesmo sendo aquele trecho largo e fundo, a fim de fugir da ação e até por medo de represálias dos ocupantes da balsa, que estava carregada com 35 caminhões e com 32 caminhoneiros e 8 tripulantes. Com as duas meninas foi apreendida uma bolsa com alguns produtos de higiene e 17 "camisinhas" (FLORENZANO, 2015). 
O rio Tajapuru se constitui em lugar de circulação e ao mesmo tempo oportunidade de sobrevivência para famílias que vivem distante dos centros urbanos, em que alijadas pela pobreza e expostas à criminalidade, representada por piratas, traficantes, aliciadores e pedófilos que não encontram barreiras ou distâncias para as suas ações que se dão em rede e que são muito bem equipadas tecnologicamente e que não respeitam isolamento social por conta de epidemias ${ }^{12}$. Então, lançamos outros questionamentos: quais as possibilidades de resistência que o Estado oferece para estas meninas e mulheres? Mas também questionamos: Quais as estratégias que estas meninas e mulheres percebem mais próxima da sua realidade? A Irmã Henriqueta que possui uma atuação de mais de dez anos no Marajó, nos diz:

\begin{abstract}
Famílias passam 2 ou 3 dias sem saber o que é colocar uma panela no fogo. Passa uma balsa, uma embarcação, elas deixam as crianças irem porque sabem que, ao retornarem, elas trazem pelo menos um litro de óleo diesel ou então alguns reais ou então alguma coisa para satisfazer a fome naquele momento.
\end{abstract}

Como indicamos ao longo deste artigo, a realidade marajoara impõe diferentes desafios para a efetivação de políticas públicas na Amazônia, em que se destacam a sua extensão territorial que vem acompanhada da forma desigual que se estruturou o capital que mesmo com territórios distantes explora e lucra com as periferias, seja pela formalidade quanto pela informalidade, em que um território que reserva uma imensa riqueza natural possui uma população em situação de pobreza extrema, que necessita dos programas de transferência de renda para sobreviver.

A Amazônia marajoara ganhou notoriedade nacional e internacional ${ }^{13}$, sendo atualmente, um dos principais alvos e plataformas de promoção política do governo vigente, que a partir de discursos e ações de caráter ultraconservador alicerçadas em posicionamentos de viés religioso e ultraliberal, sugerem

\footnotetext{
12 Indicamos a série "O mapa da fome no Brasil" do canal Repórter Record Investigação, especificamente a matéria "Crianças são abusadas por donos de balsas em troca de comida no Pará", exibida em 2018.

${ }^{13}$ Esta indicação pode ser constatada na matéria intitulada "Por que a Amazônia é o pior lugar do Brasil para ser criança” produzida pela repórter da $B B C$ News Brasil, Lígia Guimarães, publicada em setembro de 2019.
} 
estratégias pontuais para o enfrentamento de problemáticas extremamente complexas, como a exploração sexual, o trabalho infantil, a fome e o tráfico humano, que são fruto da pobreza extrema as quais estão submetidos crianças, jovens, mulheres e suas famílias.

Segundo a CNBB, em 2017, foram denunciados 365 casos de abusos e exploração sexual de crianças na região marajoara, considerando que os registros foram de 8 municípios (do total de 16), resultando numa média de duas vítimas por dia. Indicando, inclusive, que houve um crescimento de $20 \%$ ao ano ${ }^{14}$.

Recentemente, destacou-se uma nova proposta de intervenção direta para a região do Marajó das florestas e dos campos fomentadas pelo atual governo, cujo título do programa é "Abrace o Marajó" lançado no mês de julho do ano passado, no município de Breves/PA, pelo Ministério da Mulher, da Família e dos Direitos Humanos, contando com a presença da própria ministra, que juntamente à sua equipe visitou os municípios vizinhos, como Portel e Melgaço15.

Neste sentido, o Corpus que no período dos anos de 2017 a 2018 era de 31, de 2019 a 2020 (considerando os termos de busca mencionados anteriormente), aumentou especialmente por conta dos holofotes dado à região por meio das falas de gestores que passaram a incentivar a implantação de "fabricas de calcinhas" como medida de combate à exploração sexual infantil. Falas estas que receberam notas de repúdios de diferentes entidades que atuam na defesa de direitos humanos no Marajó, assim como esclarecimento por parte da autora das falas que justificou informando que estaria defendendo o fortalecimento econômico da região por meio da instalação de fábricas, e as de roupas íntimas seriam uma delas.

O grupo change.org Brasil em respostas a estas declarações apresentou os seguintes dados pautando-se nas informações do Disque 100 e a Central de Atendimento a mulher, respectivamente: nos últimos cinco anos, 895 casos de abuso e exploração sexual e 452 denúncias de agressão contra a mulher,

\footnotetext{
${ }^{14}$ Informações disponíveis em "CNBB alerta para aumento de casos de abuso e exploração sexual de crianças no Marajó” do Portal G1 Pará, de 03/07/2017.

$15 \mathrm{O}$ plano completo pode ser acessado em https://www.gov.br/mdh/ptbr/assuntos/noticias/2020-2/outubro/abrace-o-marajo-conheca-o-plano-de-acoes-doprograma-ate-2023
} 
indicando a subnotificação diante uma realidade em que a população desconhece os canais de denúncia. E acrescentamos que não haveria somente $o$ desconhecimento, mas também a ineficiência dos canais de comunicação e informação que em outros locais do país se daria pela internet ou rede telefônica. Além desses aspectos, devemos considerar a situação de precariedade econômica de famílias que vivem distantes dos centros, bem como o seu não acesso a políticas fundamentais como a assistência social e a educação, em que a título de exemplo, citamos a realidade do município de Melgaço/PA, que considerado o mais baixo IDHm do país, tem metade de sua população analfabeta, segundo dados do IBGE de 2012.

\section{Os desafios enfrentados pelas instituições de justiça e os seus profissionais}

Anteriormente apresentamos uma difícil realidade a ser superada a partir das narrativas expostas em jornais eletrônicos e páginas pessoais de opiniões que retratam uma dura realidade, porém ainda tratada de modo tendencioso por alguns que não percebem estas problemáticas em suas vivências cotidianas ou dentro de uma totalidade. Sendo comuns percepções que são atravessadas pelo machismo, sexismo, patriarcalismo, misoginia e racismo, que conformam o modo de organização do capital em áreas periféricas como a Amazônia e a América Latina.

Ao buscarmos refletir coletivamente sobre os desafios a serem enfrentados para que possamos efetivamente garantir direitos de crianças e adolescente marajoaras, num período de quatro anos, realizamos entrevistas com 35 profissionais, sendo 18 da Educação Básica, 10 da Rede Socioassistencial e 07 da Rede Sociojurídica que atuam nos municípios de Breves, Portel e Melgaço, tendo como interlocutores professores, diretores, assistentes sociais, conselheiros tutelares, psicólogos, defensores públicos e secretários municipais. Contudo, daremos especial destaque aos desafios enfrentados pela rede sociojurídica e os seus profissionais, além disto, considerando o número de entrevistados e os objetivos do artigo, daremos destaque às falas dos profissionais que atuam ou atuaram em dois ou mais municípios do Marajó seja pela demanda e missão 
institucional ou por experiência profissional. Utilizamos iniciais de nomes fictícios a fim de resguardar as suas identidades.

Em pesquisa exploratória inicial, realizada no município de Breves, foram identificados os seguintes equipamentos que trabalham diretamente com a garantia dos direitos da infância: Conselho Tutelar (CT); Conselho Municipal de Direito da Criança e Adolescente (CMDCA); Fundação PRO PAZ Integrado; Serviço de Convivência e Fortalecimento de Vínculos (SCFV); Abrigo Institucional; Delegacia Especializada no Atendimento da Criança e do Adolescente (DEACA), Pastoral da Criança e as Escolas Públicas. A inclusão das escolas parte do princípio de que estas se constituem em uma extensão da proteção e garantia dos direitos infanto-juvenis.

Destacar estes aspectos visa justamente demonstrar que o referido município enquanto cidade polo do Marajó é o que possui uma rede de proteção da infância mais completa, atendendo inclusive às demandas dos municípios vizinhos. Guimarães (2018a) ao se debruçar sobre as dinâmicas da rede de proteção no Marajó, tomando em específico o município de Breves, acaba por indicar que há descontinuidades e desconhecimentos sobre os processos de trabalhos desenvolvidos entre a rede socioassistencial e rede pública de ensino.

Comumente, os encaminhamentos e solicitações de trabalhos preventivos como atividades socioeducativas são feitas para o Conselho Tutelar por parte das escolas, estratégia correta, contudo gera a sobrecarga deste órgão municipal, na medida em que desconsidera e ignora os centros de referências de assistência social que conseguem se inserir em diferentes comunidades e incluir outras especialidades profissionais como psicólogos e assistentes sociais.

Além disso, há a compreensão de que um trabalho em rede se circunscreve somente à Política de Assistência Social, em que os profissionais que atuam na educação pública se percebem distante deste entendimento e desconhecem outros serviços e outras instituições e políticas como meios de garantia de direitos da infância. Tal processo seria sintomático da ausência de assistentes sociais que poderiam dar suporte aos professores e gestores educacionais no momento de encaminhar situações que escapassem à expertise dos profissionais da educação que teriam estar atentos às questões de ensino e aprendizagem e assim evitando 
as situações de sobrecarga que eram muito comuns nas falas dos profissionais até então entrevistados.

Guimarães (2018a) ao tratar sobre a rede de proteção da infância no município de Breves, tomando os indicativos de que o mencionado município centraliza os principais equipamentos de direitos humanos na região do Marajó Ocidental, indica os seguintes aspectos quanto o funcionamento da rede tomando em específico as escolas e os centros de referência: 1) Professores e diretores desconhecem os serviços prestados pelos Centros de Referência e os Centros de Atendimento Psicossocial; 2) As agendas de intervenção não dialogam entre si; e 3) As escolas ainda praticam as suas intervenções pautadas em perspectivas pautadas em ideais neoconservadores, caritativo e filantrópico.

A Defensoria Pública (DP) e o Ministério Público (MP), que possuem sede em Breves, fortalecem as ações de proteção da infância em diferentes municípios, porém atuam em mais de três municípios apresentando uma grande demanda para os seus profissionais. A Defensoria Pública, no dia 03 de junho de 2009, onze anos atrás, instalou o Núcleo de Atendimento Especializado da Criança e do Adolescente (NAECA) em Breves, fazendo parte do projeto de "Ampliação e regionalização do NAECA", setor voltada especificamente para a infância, tendo um histórico de atuação no estado do Pará desde 2004. Em 2012, 09 e 13 de abril, ocorreu a continuidade de suas ações em Breves e municípios vizinhos por meio do "Projeto NAECA pelo Marajó" 16.

O NAECA, ao integrar a Defensoria Pública do Estado do Pará tem como missão oferecer atendimentos de caráter interdisciplinar, judicial e extrajudicial para crianças e adolescentes que estejam em situação de vulnerabilidade pessoal ou social, assim como para seus familiares e responsáveis ${ }^{17}$. Destacamos a importância deste núcleo na DP ao especificar ações para o público infantojuvenil, partindo do entendimento que estes possuem particularidades que

\footnotetext{
${ }^{16}$ Defensoria do Pará instala Núcleo de Atendimento Especializado da Criança e do Adolescente no município de Breves <https://dppa.jusbrasil.com.br/noticias/1187177/defensoria-do-parainstala-nucleo-de-atendimento-especializado-da-crianca-e-do-adolescente-no-municipio-debreves> (de 04/06/2009) e Defensoria Pública de Breves lança o projeto "NAECA pelo Marajó" <https://dp-pa.jusbrasil.com.br/noticias/3090742/defensoria-publica-de-breves-lanca-oprojeto-naeca-pelo-maraj > (de 18/04/2012).

${ }_{17}$ Informações disponíveis na página da Defensoria Pública do Estado do Pará.
} 
necessitam ser consideradas em qualquer ação que envolva a violação de direitos, sendo fundamental a presença de equipe interdisciplinar, incluindo assistentes sociais e psicólogos.

Contudo, a DP que até então possuía o NAECA, atualmente encontra-se sem este setor que serviria para dar suporte às ações específicas para a infância e adolescência da região do Marajó, haja vista que não atende somente o município de Breves, mas também realiza trabalhos de itinerância nos municípios de Portel, Melgaço e Curralinho. Como podemos observar na fala seguinte:

\begin{abstract}
Definitivamente o quadro de profissionais é reduzido e é incompatível com o número de trabalho que a gente tem. Até porque a gente não fica só em Breves, então cada defensor faz uma itinerância, tem uma que vai pra Portel, eu vou pra Curralinho e o outro vai pra Melgaço. Só a coordenadora que fica só em Breves, mas ela tem as atividades administrativas. Então tudo isso toma muito tempo, a gente não consegue fazer um trabalho de excelência, essa que é a verdade, a Defensoria precisa mais, tanto de pessoas na atividade [...] eu vejo aqui, seria importante restabelecer o funcionamento do NAECA, que tivesse um assistente social, um psicólogo pra dá apoio pra gente (Defensor Público, 15/03/2018).
\end{abstract}

Cabendo destacar que a Defensoria Pública da região, atualmente além de não possuir mais a atuação ativa do NAECA também não dispõe de uma equipe interdisciplinar, sendo ausentes profissionais como assistentes sociais e psicólogos para atuarem em outras frentes, tais como violências contra a mulher. Confirmando o que foi relatado pelo primeiro defensor, a defensora pública expõe que:
A Defensoria Pública não tem um defensor público lotado na Comarca de Portel, sendo que existe um promotor de justiça lotado em tempo integral que atende a Comarca. O defensor público hoje realiza itinerância, então [...] um defensor de Breves pode passar uma semana por mês realizando atendimentos em Portel [...] desfalcando o atendimento em Breves (Defensora Pública, $18 / 10 / 2018$ ).

$\mathrm{Na}$ avaliação destes profissionais a ausência de uma equipe técnica completa e interdisciplinar acaba por oferecer um trabalho deficitário em municípios como Portel e Melgaço. Outros municípios como Bagre, Afuá e Anajás não possuem defensores públicos. Estes percebem uma sobrecarga de trabalho em que precisam dar respostas aos casos que necessitam de resolução e acabam por não conseguirem realizar ações mais planejadas, que não estejam pautadas 
na imediaticidade, haja vista que surgem situações como subregistro civil de nascimento, disputas pela guarda, alimentação e evasão escolar.

Em decorrência desta restrição, estes realizam as suas ações contando com a colaboração de outras instituições e organizações que tenham em sua equipe técnica, profissionais do Serviço Social e da Psicologia. Todavia, nem sempre tem as suas solicitações atendidas. Enquanto, instituições como o Fórum de Breves e o Ministério Público do Pará - Pólo Marajó II apesar de possuírem uma equipe interdisciplinar mais ampla, sentem a sobrecarga de trabalho, considerando que os profissionais não atuam somente em casos que ocorrem na cidade sede/polo/comarca.

Além de Breves, a gente tem que atender várias outras comarcas. Eles dividem a região do Marajó em dois [...] duas sub-regiões. Breves atende Bagre, Melgaço, Curralinho, Portel, São Sebastião (da Boa Vista), Chaves, Anajás [...] (Assistente Social, 29/04/2019).

O Ministério Público do Pará - Polo Marajó II possui o Grupo de Apoio Técnico Interdisciplinar (GATI) composto por uma assistente social, uma psicóloga, uma contadora e uma engenheira civil que dão subsídios às demandas solicitadas pelos promotores. Porém, conforme informação dada ao longo de nossas entrevistas foi pontuada que o GATI de Breves não estaria completo, então em casos de necessidade são realizadas solicitações ao Polo de Belém (capital do estado), que segundo a nossa entrevistada, conseguem um rápido retorno, no qual os profissionais solicitados logo se deslocam para Breves a fim de dar o suporte necessário.

Contudo, devemos sempre visualizar que apesar dos esforços empreendidos para que estas instituições estejam presentes na região, infelizmente, acaba não se dando de forma plena e efetiva, pois fatores como desconhecimento do território e os constantes "ir e vir" dos profissionais contratados e concursados impedem que as ações se dêem num marco de continuidade, pois este mesmo território, dado a estes condicionantes, sempre será um espaço desconhecido ou compreendido pela metade.

Considerações neste sentido podem ser observadas nas indicações da defensora pública que ao se referir ao NAECA, salienta que para a sua existência é necessário que existam profissionais especializados na área da infância, o que 
ainda não existe na região do Marajó, então para sanar esta situação são feitas solicitações de profissionais da capital do estado. Vejam:

\begin{abstract}
O NAECA em Belém tem um grupo de defensores que têm essa especialização e eles ficam disponíveis para nos auxiliar sempre que precisarmos. Então temos uma demanda muito específica, que exige um conhecimento aprofundado. Temos meios de acessar, só que aqui em Breves, apesar de ser o núcleo regional é um atendimento a uma área muito grande, uma população muito grande, tanto a área em termos físicos [...] a extensão de terra abrangida, quanto o número de pessoas potencialmente atendidas é muito grande. Não se consegue por conta disso. Não temos como ter um defensor lotado só na área de infância, porque sendo três defensores, e os três fazendo itinerância, cada um acumulando outra Comarca. Não, não tem como! É humanamente impossível atender com qualidade tudo isso (Defensora Pública, 18/10/2018).
\end{abstract}

Aliado às solicitações de profissionais efetivos de outros municípios, também há a constante rotatividade de profissionais em regime de contrato ligadas às mudanças de gestão municipais, estando mais afeitos às pressões políticas, sendo poucas as instituições que possuem um quadro fixo de profissionais. Consequentemente há grandes dificuldades para a consolidação de um trabalho articulado em rede, haja vista que os contatos e registros vão sendo perdidos.

As dificuldades relacionadas às restrições do número de profissionais acabam por não contribuir na realização de um trabalho mais sistematizado, que possa passar por um processo de reflexão e ação. Comum nas falas à ausência de dados sistematizados, que estaria relacionado à extensão da atuação das instituições perante o amplo território marajoara. Situação causada pelas restrições orçamentárias que atingem as diferentes políticas sociais não somente no Marajó, mas no país como um todo. Contudo, acaba sendo muito mais impactante em regiões que extrapolam modelos de políticas que ainda compreendem os territórios a partir dos centros.

\title{
Considerações finais
}

Como indicado no início desse texto, os registros aqui realizados são frutos de amadurecimento acadêmico que se deram da saída da linha de pesquisa da história da infância da Amazônia para refletir sobre a atualidades desta mesma 
infância, contudo a partir das falas daqueles que são responsáveis pela efetivação de sua proteção e segurança por meio de políticas públicas, numa perspectiva de direito a ser garantido, não mais como caridade e filantropia pautadas em uma compreensão paternalista de Estado, tal como iremos encontrar nos discursos dos intelectuais de finais do século XIX e início de XX.

Del Priore e Venâncio (2010) sabiamente nos dizem que para compreender o presente precisamos entender o nosso passado, mas a infância no qual tratamos nestas linhas é justamente aquela que não teve nem mesmo o direito de ter a sua história registrada, nem pelo discurso dos adultos dos séculos XIX e XX. Nas longas narrativas dos que são de fora, o século XX seria o século da criança, no qual intelectuais e representantes políticos passaram a rejeitar situações em que crianças estivessem nas fábricas trabalhando, passando fome e fora da escola. Em torno deste debate sobre mobilização pela infância e criação de políticas específicas se refere também ao entendimento e representações de infância.

Vivemos e experienciamos uma sociedade que por ser racista é também genocida, que aniquila corpos e sonhos a partir de criações de padrões e idealizações de sujeitos, e por consequência acabam por atingir também as nossas infâncias e crianças. Mobilizam-se com muito mais afinco e estarrecimento por infâncias brancas, da elite e que façam parte dos centros. Enquanto isso, crianças não brancas, que vivem na pobreza e em nossas periferias junto às suas mães, em mesma condição de vulnerabilidade, são obrigadas a criarem suas próprias estratégias de sobrevivência diante de um Estado ainda ausente, distante e desconhecido.

As nossas considerações tratando sobre a entrada das demandas da infância nas políticas públicas, dando especial ênfase aos conceitos de rede e sistema, visa justamente apreendermos que as ações para a garantia dos direitos humanos de crianças e adolescentes tem por obrigação serem qualificadas, a fim de termos como suportes diferentes estratégias que contribuam para a construção de um trabalho colaborativo e coletivo que inclua diferentes instituições e políticas, tendo como principal foco acompanhar a infância nos diversos espaços a qual circula. Logo, a escola e a família são primordiais, sendo importante a 
primeira ser compreendida como um prolongamento da rede socioassistencial, assim como a segunda deve ter garantida a sua proteção.

A intenção primeira deste texto seria a de quebrarmos narrativas e construções teóricas que homogeneízam a história da infância e a relatam a partir do discurso do centro que se faz único e hegemônico, silenciando sujeitos que ainda lutam por direitos que em outros contextos e realidades são tidos como comuns e básicos. A história da infância marajoara vem sendo escrita e registrada por movimentos sociais, gestores e pesquisadores que visam combater os graves casos de violações vividos por crianças no Marajó, mas também tem servido como estratégia de promoção política que acaba por vulnerabilizar ainda mais esta infância colocando-a como sujeito passivo perante a sua própria história.

São ainda comuns situações em que gestores e instituições importantíssimas para a garantia de direitos humanos acreditarem ou fazer acreditar que os casos de violações serão resolvidos com um dia de visita realizada por pessoas de fora que não tem a mínima noção sobre as dinâmicas e dimensão do seu território. A Amazônia desafia gestores, intelectuais e as Novas Tecnologias de Comunicação e Informação. Há comunidades que ainda não estão indicadas no Google Maps e que apesar de estar num mesmo município para se ter acesso precisamos realizar viagens de doze horas de navio sem qualquer sinal de rede telefônica ou de internet.

Por consequência, tivemos relatos de defensores públicos que a afirmam que uma das principais problemáticas a serem enfrentadas seria a ausência de registros em que existem famílias inteiras, com cinco a oito membros que não possuem seus nomes registrados, sendo impedidos de terem acesso a serviços básicos, tornando-os inexistentes para o Estado, como foi sinalizado por um dos nossos entrevistados.

A nossa segunda intenção seria a de fortalecer as práticas extensionistas e o ensino por meio das ações de pesquisa. A pesquisa guiada pelo entendimento de que seria momento de diálogo com os profissionais (que em sua maioria são de outras regiões) e os moradores dos rios, florestas e campos marajoaras, consequentemente, a extensão estaria sendo realizada com atividades formativas que tem como horizonte as rodas de conversas que possibilitem refletir sobre o 
território, os desafios e as potencialidades que os Marajós e os seus sujeitos possuem.

Diante da complexa realidade exposta ao longo desta pesquisa é fundamental estarmos abertos ao constante diálogo com os profissionais que atuam direta e indiretamente na proteção da infância, compreendendo quais os aspectos que atualmente impedem a realização de ações em rede que possam ir para o enfrentamento deste contexto tão cruel para a infância marajoara.

Este trabalho pretende acima de tudo dar visibilidade e perquirir sobre violações de direitos humanos que atingem crianças e adolescentes dos municípios de Breves, Curralinho, Portel e Melgaço, pertencentes à região do Marajó Ocidental. Atualmente, estamos nos articulando no sentido de realizarmos este levantamento nestes municípios atualizando os dados sobre as violações e estabelecer um estudo ampliado e comparativo com a Região do Baixo Tocantins que também possuem municípios com baixo IDH, cercado por rios, contudo não surge nos discursos nacionais como "lugar" de violações dos direitos da infância. Mas quais os motivos, dinâmicas e condicionantes que fazem da mencionada região estar em um patamar diferenciado quando comparado com a região do Marajó?

São reflexões que precisam ser impulsionadas com a finalidade de registrarmos as histórias das infâncias que não vivem nas capitais do Brasil e da Amazônia, percebendo a importância da pesquisa e da universidade pública também como um importante agente articulador da rede e que também deve estar inserido como uma extensão do sistema de garantia de direitos de crianças e adolescentes, haja vista que forma e capacita os presentes e futuros profissionais que irão trabalhar direta e indiretamente com a infância. 
Revista Brasileira de História \& Ciências Sociais - RBHCS

Vol. $13 \mathrm{~N}^{\circ}$ 25, Edição Especial de 2021

\section{REFERÊNCIAS}

A Covid-19 no Marajó. Jornal Liberal 1. Belém: TV Liberal Belém. 01 de julho de 2020.

A Defensoria do Pará instala o Núcleo de Atendimento Especializado da Criança e do Adolescente no município de Breves. JusBrasil, postado pela Defensoria Pública, 04 de jun. de 2009. Disponivel em $<$ https://dppa.jusbrasil.com.br/noticias/1187177/defensoria-do-para-instalanucleo-de-atendimento-especializado-da-crianca-e-do-adolescente-nomunicipio-de-breves $>$. Acesso: 10/04/2020.

\section{A Defensoria Pública de Breves lança o projeto "NAECA pelo}

Marajó". JusBrasil, postado pela Defensoria Pública, 18 de abril. de 2012. Disponível em <https://dp-pa.jusbrasil.com.br/noticias/3090742/defensoriapublica-de-breves-lanca-o-projeto-naeca-pelo-marajo > . Acesso: 10/04/2020.

BRASIL, Ministério da Mulher, da Família e dos Direitos Humanos. Programa Abrace o Marajó: Plano de Ação de 2020-2023. Brasília: MMFDH, 2020. Disponivel em < https://www.gov.br/mdh/pt-br/assuntos/noticias/20202/outubro/abrace-o-marajo-conheca-o-plano-de-acoes-do-programa-ate2023/19.10.2020VersoFINALPlanodeAcaoAbraceoMARAJO20202023.pdf $>$. Acesso: 20/10/2020.

BRASIL, Ministério da Saúde. Diagnóstico e Tratamento da COVID-19, publicado no dia 7 de maio de 2020, Brasília, DF, 2020.

BRASIL. Lei 8.069, de 13 de julho de 1990. Dispõe sobre o Estatuto da Criança e do Adolescente e dá outras providências. Diário Oficial [da] República Federativa do Brasil, Brasília, DF, 16 jul. 1990.

Breves enfrenta colapso da saúde e caos no sistema funerário durante a pandemia de Covid-19. Jornal Eletrônico G1 Pará, Belém, o1 de jul. de 2020. Disponivel em

<https://g1.globo.com/pa/para/noticia/2020/07/01/breves-enfrenta-colapsoda-saude-e-caos-no-sistema-funerario-durante-a-pandemia-de-covid19.ghtml>. Acesso em: 02/07/2020.

BOGÉA, Hiroshi. Sefer em dois tempos. Hiroshibogéa Online. Disponível em $<$ https://www.hiroshibogea.com.br/sefer-em-dois-tempos/>. Acesso: 01/12/2020.

CARNEIRO, Tayma. Bolsonaro chega em Breves, no PA, para apresentar programa social. TV Liberal, G1 PA, Belém, 08 de out. de 2020. Disponível em < https://g1.globo.com/pa/para/noticia/2020/10/o8/bolsonaro-chega-embreves-no-pa-para-apresentar-programa-social.ghtml>. Acesso em: $09 / 10 / 2020$

CNBB alerta para aumento de casos de abuso e exploração sexual de crianças no Marajó. Jornal Eletrônico G1 Pará, Belém, o3 de jul. de 2017. Disponivel em <https://g1.globo.com/pa/para/noticia/cnbb-alerta-para-aumento-de- 
casos-de-abuso-e-exploracao-sexual-de-criancas-no-marajo.ghtml> . Acesso em: 04/07/2017.

Covid-19: em novo pico, Amapá registra 639 novos casos em um dia e chega aos 5 mil infectados. Jornal Eletrônico G1 Amapá, Macapá, 21 de mai. de 2020. Disponivel em < https://g1.globo.com/ap/amapa/noticia/2020/05/21/covid19-em-novo-pico-amapa-registra-639-novos-casos-em-um-dia-e-chega-aos-5mil-infectados.ghtml>. Acesso em: 02/07/2020.

Crianças e adolescentes: Balanço do Disk 100 aponta mais de 76 mil vítimas. Governo Federal/Ministério da Mulher, da Família e dos Direitos Humanos. Disponível em < https://www.gov.br/mdh/pt-

$\mathrm{br} /$ assuntos/noticias/2019/junho/criancas-e-adolescentes-balanco-do-disque100-aponta-mais-de-76-mil-vitimas >. Acesso em: 09/10/2020.

CUNHA, Paulo Roberto. O novo governo e a Amazônia: desproteção ambiental e privatização de terras públicas. Confins [Online], 501, 2019, postado online no dia o9 setembro 2019. Disponível em:

<http://journals.openedition.org/confins/21149>. Acesso em 19/11/2019.

DEL PRIORE, Mary; VENÂNCIO, Renato. Uma breve história do Brasil.

São Paulo: Editora Planeta do Brasil, 2010.

FEARNSIDE, Philip Martin. Retrocessos sob o Presidente Bolsonaro: Um desafio à sustentabilidade na Amazônia. Sustentabilidade International Science Journal, v.1, n.1. 2019, abril/junho, p. 38-52.

FIALHO NASCIMENTO, Nádia Socorro. Amazônia e Desenvolvimento Capitalista: a centralidade da região para a acumulação de capital e a produção das expressões da "questão social". Revista de Políticas Públicas. Número especial, p. 203-213, agosto de 2010.

FLORENZANO, Franssinete. O drama das meninas balseiras no Marajó. Blog, 16 de mar. de 2017. Disponível em <http://uruatapera.blogspot.com.br/2015/o3/a-tragedia-das-meninasbalseiras-no.html/> . Acesso em: 27/10/2017.

GARRETT Jr., Gilson. Veja os estados mais e menos afetados proporcionalmente pela COVID-19. Revista Exame. Brasil, 23 de mai. de 2020. Disponível em < https://exame.com/brasil/veja-os-estados-mais-emenos-afetados-proporcionalmente-pela-covid-19/> . Acesso em: 22/06/2020.

GIDDENS, Anthony; SUTTON, Philip W. Conceitos essenciais da Sociologia. - 2. Ed. - São Paulo: Editora UNESP, 2017.

GUEDES, Leonildo Nazareno do Amaral. A participação das escolas de ensino fundamental de Breves-PA no enfrentamento da exploração sexual de crianças e adolescentes. Dissertação de Mestrado. Universidade Federal do Pará. Programa de Pós-graduação em Educação, Belém, 2012.

GUIMARÃES, Jacqueline Tatiane da Silva. A infância no Marajó

Ocidental: considerações sobre o município de Breves. In: XVI Encontro Nacional de Pesquisadores em Serviço Social, 2018. Vitória/ES. Anais ... Vitória/ES: ENPESS/UFES, 2018. 
GUIMARÃES, Jacqueline Tatiane da Silva. A proteção da infância no município de Breves (Marajó/PA). In: IV Jornada Nordeste de Serviço Social, 2018. João Pessoa/PB. Anais .... João Pessoa/PB: Jornada Nordeste de Serviço Social/UFPB, 2018.

GUIMARÃES, Ligia. Por que a Amazônia é o pior lugar do Brasil para ser criança. Jornal Eletrônico BBC News, Brasil, o5 de nov. de 2019. Disponível em < https://g1.globo.com/natureza/noticia/2019/11/o5/por-quea-amazonia-e-o-pior-lugar-do-brasil-para-ser-crianca.ghtml>. Acesso em: $06 / 11 / 2019$.

INSTITUTO BRASILEIRO DE GEOGRAFIA E ESTATÍSTICA (IBGE).

Disponível em <https://www.ibge.gov.br/cidades-e-estados > . Acesso em: 07/07/2020.

JOHNSON, Allan G. Dicionário de sociologia: guia prático da linguagem sociológica. - tradução, Ruy Jungmann; consultoria, Renato Lessa. - Rio de Janeiro: Jorge Zahar Ed., 1997.

JUNQUEIRA, Luciano A. Prates. A gestão intersetorial das políticas sociais e o terceiro setor. Saúde e Sociedade, São Paulo, v. 13, n. 1, p. 25-36, jan./abr. 2004.

JUNQUEIRA, Luciano A. Prates; INOJOSA, Rose Marie; KOMATSU, Suely. Descentralização e intersetorialidade na gestão pública municipal no Brasil: a experiência de Fortaleza. In: do XI Concurso de Ensayos del Clad "El Tránsito de la Cultura Burocrática al Modelo de la Gerencia Pública: Perspectivas, Posibilidades y Limitaciones”. Caracas, 1997/Anais ... Caracas, 1997.

MAGALHÃES, João Carlos. Crianças de Marajó se prostituem por hot dog (são exploradas sexualmente). Blog Infância Urgente, 22 de jun. de 2009. Disponível em

<http://infanciaurgente.blogspot.com.br/2009/o6/criancasdemarajoseprostitu empor.html $>$. Acesso em: 01/07/2017.

MENDES, Carlos. A venda de criancas para sexo no Marajo. Bacana News, 23 de jun. de 2017. Disponivel em < https://bacana.news/venda-de-criancas-parasexo-no-marajo/>. Acesso em: 20/04/2018.

Missão do NAECA. Portal da Defensoria Pública do Estado do Pará. Disponível em <http://www2.defensoria.pa.def.br/portal/naeca/index.html $>$. Acesso em 10/04/2020.

NASCIMENTO, Sueli do. Reflexões sobre a intersetorialidade entre as políticas públicas. Serviço Social e Sociedade, São Paulo, n. 101, p. 95-120, jan./mar. 2010

OBSERVATÓRIO DO MARAJÓ/LUTE SEM FRONTEIRAS. 4 o dias de Marajó com Coronavírus. Cadernos do Marajó - Edição Especial, publicado no dia 01/o6/2020. Disponível em <www.observatoriodomarajo.org $>$. Acesso: 01/06/2020. 
O que é o IDH. Disponível em

<https://www.br.undp.org/content/brazil/pt/home/idho/conceitos/o-que-e-o$\mathrm{idh} />$. Acesso em: 20/03/2020.

O mapa da fome no Brasil - Crianças são abusadas por donos de balsas em troca de comida no Pará. Repórter Record Investigação, 30 de jul. de 2018. Disponível em < https://www.youtube.com/watch?v=iPuQ8e3ZBo8>. Acesso em: 20/08/2018.

Pará é o segundo estado do Brasil com mais pontos de exploração sexual infantil nas estradas. Jornal Eletrônico G1 Pará, Belém, 15 de mai. de 2018.

Disponivel em <https://g1.globo.com/pa/para/noticia/2020/o7/o1/brevesenfrenta-colapso-da-saude-e-caos-no-sistema-funerario-durante-a-pandemiade-covid-19.ghtml>. Acesso em: 02/06/2020.

PARÁ, Assembleia Legislativa do Estado do Pará (ALEPA). Comissão Parlamentar de Inquérito. Instituída para apurar a prática de violência e abuso sexual contra crianças e adolescentes no estado do Pará e especialmente na região do Marajó nos último cinco anos. Belém/PA, 2010. Disponível em

<https://www.alepa.pa.gov.br/midias/midias/130_9485ddc9ce29459bab18271 4468fda33.pdf $>$. Acesso em: 01/12/2020.

PARANÁ, Ministério Público do. Tecendo redes: fortalecimento das redes de proteção à infância e à adolescência no Paraná/ Rede Marista de Solidariedade, Ministério Público do Paraná. -- Curitiba: Editora Champagnat, 2014.

PROGRAMA DAS NAÇÕES UNIDAS PARA O DESENVOLVIMENTO (PNUD Brasil). Ranking IDHM Municípios 2010. Disponível em <https://www.br.undp.org/content/brazil/pt/home/idho/rankings/idhmmunicipios-2010.html > . Acesso em 22/o8/2017.

Relatório sobre Exploração Sexual em Portel. Disponível em $<$ https://www2.camara.leg.br/atividade-legislativa/comissoes/comissoespermanentes/cdhm/documentos/relatorios/relexpsex $\geq$. Acesso em: 14/03/2017.

SEVERINO, Antonio Joaquim. Metodologia do Trabalho Científico. 23 ed. rev. e atual. - São Paulo: Cortez, 2007.

SILVA, Joel Pantoja da. Memórias Tupi em narrativas orais no rio Tajapuru: Marajó das Florestas/PA. 2013. 152f. (Mestrado em Comunicação, Linguagens e Cultura) Universidade da Amazônia, Belém, 2013. TEIXEIRA, Joaquina Barata. Meio Ambiente, Amazônia e Serviço Social. Revista em Pauta, n. 21, p. 140 -152, 2008.

Trabalho rouba infância no Marajó. O Liberal, Belém, 10 de mai. de 2007. Disponível em $<$ http://gvces.com.br/trabalhoroubainfancianomarajo?locale=ptbr $>$. Acesso em: 22/07/2017. 
Revista Brasileira de História \& Ciências Sociais - RBHCS

Vol. $13 \mathrm{~N}^{\circ}$ 25, Edição Especial de 2021

UNICEF. Agenda pela Infância e Adolescência na Amazônia, 2018. Disponível em

<https://www.unicef.org/brazil/media/1131/file/Agenda_pela_infancia_e_ado lescencia_na_Amazonia.pdf $>$. Acesso em 19/12/2018. 